\title{
La Condición más beneficiosa en la Pensión de Invalidez y Sobrevivientes desde la Jurisprudencia Colombiana
}

\section{The Most Beneficial Condition in the Invalidity and Survivors Pension from Colombian Jurisprudence}

\author{
DOI: https://doi.org/10.17981/juridcuc.15.1.2019.05
}

Fecha de Recepción: 18/02/2019 Fecha de Aceptación: 18/06/2019

\author{
Alberto E. Barrios Lozano \\ Universidad de la Costa, Barranquilla (Colombia) \\ abarrios13@cuc.edu.co/
}

\author{
Ligia Cielo Romero Marín \\ Universidad de la Costa, Barranquilla (Colombia) \\ lromero11@cuc.edu.co
}

Para citar este artículo:

Barrios, A. y Romero, L. (2019). La Condición más beneficiosa en la Pensión de Invalidez y Sobrevivientes desde la Jurisprudencia Colombiana. JURÍDICAS CUC, 15(1). 135-162. http:// dx.doi.org/10.17981/juridcuc.15.1.2019.05

Resumen

El principio de la condición más beneficiosa, constituye un fundamento jurisprudencial para el reconocimiento de las pensiones de invalidez de origen común y de sobrevivientes. En lo relacionado con su aplicación existen diferencias entre la Corte Constitucional y la Sala Laboral de la Corte Suprema de Justicia, en cuanto a los límites temporales que se deben tener en cuenta para estudiar el derecho; mientras la Corte Constitucional hace una revisión en regreso de las normas derogadas, la Corte Suprema de Justicia solo examina la disposición abolida inmediatamente anterior. Para tales efectos, se hace una revisión bibliográfica jurisprudencial y documental a partir de los límites de aplicación de la condición más beneficiosa, con el propósito de analizar cuál de los dos criterios resulta favorable. En términos generales se puede concluir como la regla de la Corte Constitucional es mas favorable que la expuesta por la Corte Suprema de Justicia.

Palabras clave: condición más beneficiosa; retrospectividad; expectativa legítima; jurisprudencia; pensión de invalidez; pensión de sobrevivientes.

\section{Abstract}

The principle of the most beneficial condition constitutes a jurisprudential basis for the recognition of invalidity pensions of common origin and of survivors. With regard to the application of this principle, there are differences between the Constitutional Court and the Labour Chamber of the Supreme Court of Justice in terms of the time limits that must be taken into account when studying the law; since, while the Constitutional Court reviews the repealed norms, the Supreme Court of Justice only examines the immediately preceding abolished provision. To this end, a bibliographic review of case law and documents is carried out starting from the limits of application of the most beneficial condition, with the purpose of analyzing which of the two criteria is favorable. In general terms, it can be concluded that the rule of the Constitutional Court is more favorable than that set forth by the Supreme Court of Justice.

Key Word: most beneficial condition; retrospectivity; legitimate expectation; jurisprudence; disability pension; survivor's pension. 


\section{INTRODUCCIÓN}

Desde hace varias décadas se viene abriendo camino en el trasegar jurídico, un nuevo sistema de seguridad social, considerado como aquella reglamentación o conjunto de normas que apoyan el desarrollo del Derecho Laboral, en temas concretos como la salud, los riesgos en el trabajo y las pensiones. En ese sentido, el preámbulo de la Ley 100 (1993) consagra:

El sistema de seguridad social integral es el conjunto de instituciones, normas y procedimientos de que dispone la persona y la comunidad para gozar de una calidad de vida, mediante el cumplimiento progresivo de los planes y programas que el Estado y la sociedad desarrollan para proporcionar la cobertura integral de las contingencias, especialmente las que menoscaban la salud y la capacidad económica de los habitantes del territorio nacional (p. 1).

De acuerdo al anterior concepto de seguridad social, el Estado procura reconocer prestaciones asistenciales y económicas a los habitantes de este territorio, para mejorar sus condiciones de vida, dado el acaecimiento de circunstancias como la enfermedad, la vejez, la invalidez o la muerte, y sin ingresos continuos y permanentes, los cuales les permitan sufragar o atender las necesidades del afiliado y de sus familias, necesariamente comprometen otros derechos fundamentales, como la dignidad humana y el mínimo vital; y es obligación del Estado cumplir sus fines esenciales como lo expresa la Constitución Política de Colombia (CP. 1991, Art. 1), al "garantizar la efectividad de los principios, derechos y deberes consagrados en la Constitución" (CP. 1991, Art. $2^{\circ}$ ). En el mismo sentido, Romero e Ibarra (2017) expresan:

Colombia para los años noventa se encontraba en una situación de crisis aguda debido a fenómenos como la apertura económica, la globalización, el narcotráfico, el desempleo, el subempleo y la corrupción; este estado de cosas exigía un cambio en 
las estructuras económicas, sociales y jurídicas. Un grupo de estudiantes universitarios propuso reformar la Constitución Política, hecho que culminó con la elección de una Asamblea Nacional, lográndose dar paso a un Estado social de derecho (p. 43).

Conforme a lo expresado, aprobada la Constitución de 1991 se da paso a un Estado social de derecho y a la creación de disposiciones que sirvieron de fundamento para la creación de la (Ley 100, 1993) donde subyace el origen jurídico del principio de la condición más beneficiosa, eje central del presente estudio, por ser fuente de derecho para la obtención de la pensión de invalidez de origen común y de sobrevivientes, en atención a que el legislador no consagró, en los diferentes cambios legislativos, un régimen de transición que protegiera o salvaguardara las expectativas legítimas de quienes en normas derogadas reunieron la densidad de semanas necesaria para alcanzar dicha prestación pensional; ante un evento futuro, inesperado o intempestivo, como la discapacidad y la muerte; como si lo hizo, con la pensión jubilación y de vejez, en varias ocasiones.

Vale recordar el último régimen de transición introducido (Ley 100, 1993, Art. 36), su versión original, el cual conservaba los requisitos de la pensión de vejez para las personas que durante la entrada en vigencia de la citada ley tenían cumplida una edad determinada o habían acumulado cierto número de semanas o tiempo de servicio; pero, esta transición quedó consagrada únicamente para la pensión de vejez, más no para la de invalidez, ni para la de sobrevivientes, por tal razón, tanto la Sala Laboral de la Corte Suprema de Justicia como la Constitucional vieron en la condición más beneficiosa, el instrumento constitucional que permite respectar las expectativas legitimas logradas en normas derogadas por otras que resultaron regresivas, poniendo en riesgo el acceso a la pensión de invalidez de origen común y de sobrevivientes de estas personas. 
Resulta indudable, con la introducción de este principio de la condición más beneficiosa, en el sistema jurídico colombiano, tanto la Corte Constitucional como la Sala Laboral de la Corte Suprema de Justicia han procurado morigerar, allanar o compensar el vacío causado por la ausencia del citado régimen de transición, en el sistema general de pensiones.

Sobre el anterior principio, las cortes coinciden en: su origen constitucional, en su constitución como un instrumento de protección a las expectativas legítimas consolidadas en la vigencia de normas derogadas, es una excepción a la aplicación inmediata de la ley, a la retrospectividad de la misma y constituye un ejemplo al principio de ultractividad de la ley.

Sin embargo, existe una diferencia entre las citadas cortes, en cuanto al campo de aplicación de este principio en la pensión de invalidez y sobrevivientes, al seducir por llevar a cabo el abordaje de este el tema.

\section{Origen jurisprudencial del principio}

La condición más beneficiosa fue definida por la Corte Constitucional en la sentencia T-190 (2015) "como una institución jurídica por medio de la cual, frente a un cambio normativo, una disposición legal derogada del ordenamiento cobra vigencia para producir efectos jurídicos en una situación concreta”. Según la citada definición, la condición más beneficiosa produce un efecto ultractivo al permitir a una ley derogada producir resultados o consecuencias hacia el futuro, en la medida en que los cambios legislativos consagren requisitos regresivos poniendo en riesgo el derecho a obtener la pensión de invalidez de origen común y la de sobrevivientes.

En ese sentido, la honorable Corte Constitucional en la sentencia SU-120/03 (2003) consagró el principio de interpretación más favorable en materia laboral en los siguientes términos: 
La Sala accionada deberá considerar que el artículo 53 de la Constitución Política impone al intérprete de las fuentes formales del derecho laboral el criterio de elegir, en caso de duda, por la interpretación que más favorezca al trabajador, y en consecuencia optar por ordenar a las entidades financieras obligadas mantener el valor económico de la mesada pensional de los actores, por ser ésta la solución que los beneficia y que condice con el ordenamiento constitucional Corte Constitucional (Sentencia SU-120, 2003)

La consagración del principio de la condición más beneficio$s a$ en la seguridad social, encuentra su fundamento jurídico en un núcleo de derechos consagrados en la Constitución de 1991: "el derecho irrenunciable a la seguridad social" (CP. 1991, Art. 48), "la protección de las personas que por sus condiciones de salud se encuentran en circunstancias de debilidad manifiesta" (CP. 1991, Art. 13), "la protección a los disminuidos físicos, sensoriales y síquicos" (CP. 1991, Art. 47), "obrar conforme al principio de solidaridad social” (CP. 1991, Art, 48; CP. 1991, Art. 95), "buena fe" (CP. 1991, Art. 83), "asegurar los deberes sociales del Estado" (CP. 1991, Art. 2), la condición "según la cual la ley, los contratos, los acuerdos y convenios de trabajo, no pueden menoscabar la libertad, la dignidad humana ni los derechos de los trabajadores" (CP. 1991, Art. 53), los cuales deben "interpretarse a la luz de los tratados internacionales de derechos humanos ratificados por Colombia" (CP. 1991, Art. 93), e incorporados a la legislación interna, entre los cuales se reseña el Protocolo de San Salvador, aprobado mediante la Ley 319 (1996) que señala a la seguridad social como el derecho que tiene toda persona a que se le "proteja contra las contingencias de la vejez y de la incapacidad que la imposibilite física o mentalmente para obtener los medios para llevar una vida digna y decorosa (CP. 1991, Art. 9)" y tal como se encuentra reseñado en la sentencia SU-442 (2016) de la Corte Constitucional. 
El anterior compendio de derechos y obligaciones, se recalca, conforman el núcleo esencial del principio de la condición más beneficiosa, de aplicación excepcional en el sistema de seguridad social, cuando se trata del reconocimiento de las pensiones de invalidez y de sobrevivientes, el cual la Corte Constitucional, según la citada sentencia SU-442, comenzó a aplicar desde el fallo de la tutela T-1058 (2010), data desde la cual se ha venido utilizando con algunos ajustes, por las diferentes salas de revisión de esta corporación.

Así mismo, este principio encuentra fundamento en lo expresado por algunos autores como Hernández, Chumaceiro, Ziritt y Acurero (2018) en cuanto a lo que señalan sobre "la democracia como sistema político requiere unos soportes jurídicos, institucionales, ciudadanos y societales que garanticen su funcionamiento, el marco normativo, la legitimidad, legalidad, la gobernanza, son mínimos exigibles para su aplicación” (p. 616).

\section{Características de la condición más beneficiosa}

Para la Sala Laboral de la Corte Suprema de Justicia, las características del principio de la condición más beneficiosa, estan vertidas en la sentencia SL-4650 (2017), la cual está referida a:

i. "Es una excepción al principio de retrospectividad", teniendo en cuenta la aplicación de la nueva ley a situaciones anteriores no consolidadas, que se encuentran en curso al momento de entrar en vigencia la nueva disposición, siendo esta la regla general, porque, situación contraria o diferente ocurre con la condición mas beneficiosa al desestimar la norma vigente por desfavorable para aplicar una norma derogada hacia el futuro. De otra parte, el principio de retrospectividad hace efectivo la aplicación inmediata de la ley, mientras, el de la condición mas beneficiosa lo desestima. 
ii. "Aplica por el paso de una legislación a otra", en los eventos que el cambio haga más gravoso los requisitos para el afiliado o sus causahabientes alcanzar la pensión de invalidez de origen común o de sobrevivientes. Es en este caso, cuando la condición más beneficiosa surge para preservar los derechos, ante la ausencia de un régimen de transición que los resguarde, al constituir la transición, de manera general, en "un mecanismo de protección para que los cambios producidos por un tránsito legislativo no afecten desmesuradamente a quienes, si bien no han adquirido el derecho a la pensión, por no cumplir con los requisitos para ella, tienen una expectativa legítima de adquirir ese derecho por la proximidad a cumplir los requisitos para pensionarse, en el momento del tránsito legislativo" (Sentencia C-789, 2002), teniendo en cuenta que el Estado no puede cambiar la ley de manera súbita sin observar la forma en que puede afectar expectativas legítimas o comportar una regresividad de derechos.

iii. "Procede cuando se predica la aplicación de la normatividad inmediatamente anterior a la vigente al momento del siniestro" (Sentencia SL-4650, 2017), esta característica corresponde al límite temporal que ha fijado la Sala Laboral de la Corte Suprema de Justicia para la aplicación del principio de la condición más beneficiosa, al no admitir realizar la búsqueda del derecho pretendido en normas derogadas más antiguas por afectar la sostenibilidad financiera del sistema.

iv. "Entra en vigencia solamente a falta de un régimen de transición" (Sentencia SL-4650, 2017), tal como se ha señalado antes, la ausencia de un regímen de transición deja desprotegidas las expectativas legítimas consolidas bajo el imperio de normas suprimidas, por las cuales el afiliado no alcanza los requisitos para lograr el derecho, entonces, el principio allana este defecto para salvar el derecho. 
v. "Protege las expectativa legítimas de las personas poseedoras de una situación jurídica y fáctica concreta", en cuanto a la expectativa legítima, también llamada por la jurisprudencia "derecho eventual", el cual busca proteger la consolidación de "una situación fáctica y jurídica concreta en virtud de la satisfacción de alguno de los requisitos relevantes de reconocimiento del derecho subjetivo" tal como lo reseña la Corte Constitucional (Sentencia T-832A, 2013). Expectativa que difiere de los derechos adquiridos que se configuran o consolidan con el cumplimiento de todos los requisitos establecidos en la Ley, confiriéndole al afiliado el estatus de pensionado, la facultad de reclamar la pensión en cualquier tiempo, la seguridad jurídica de su derecho a no ser desmejorado o modificado negativamente y a reclamarlo o hacerlo efectivo en cualquier tiempo.

Sin embargo, la Corte Constitucional en la sentencia T-832A, (2013), señala que las expectativas legitimas pueden verse afectadas negativamente por el tránsito legislativo, pero la desmejora debe estar fundada en "parámetros de justicia y equidad", en razón a "que toda actividad del Estado debe sujetarse a los principios de racionalidad y proporcionalidad".

vi. "Respeta la confianza legítima de los destinatarios de la norma", cuando un afiliado consolida una expectativa legítima para acceder a la pensión de invalidez de origen común o de sobrevivientes, por haber reunido las semanas requeridas en determinado régimen de seguridad social, siente la satisfacción y la tranquilidad de tener asegurada la prestación pensional, en los casos que ocurra la invalidez o se ocasione la muerte, es por esto, que los cambios legislativos que afecten esta expectativa, generan en la persona una sensación de inestabilidad, preocupación y desconfianza, pero procurando a las Cortes mitigar aplicando el principio de la condición más beneficiosa. 


\section{Aplicación de la condición más beneficiosa}

en la pensión de invalidez y sobrevivientes

El acceso a estas prestaciones, se obtiene cuando el afiliado o pensionado, según el caso, reúne los requisitos contemplados en las disposiciones vigentes a la fecha de la estructuración de la discapacidad o muerte, sin embargo, parafraseando a la Sala Laboral - Corte Suprema de Justicia, la jurisprudencia cuando se cumple con la densidad de semanas de cotización, dentro del plazo estrictamente exigido por la normatividad aplicable ha entendido que debe configurar una situación jurídica concreta, traducida en una expectativa legítima (Sentencia SL-4650, 2017).

Para tal efecto, la condición más beneficiosa surge como un instrumento jurídico para defender las expectativas legítimas concretadas en vigencia de normas derogadas, al no tener respuesta el derecho, implorado en la norma vigente a la fecha de la causación del suceso siniestro.

Sin embargo, en la aplicación de la condición más beneficiosa existe una fuerte diferencia entre la Corte Suprema de Justicia, Sala Laboral y la Corte Constitucional, pues, mientras la primera de las corporaciones citadas establece un campo de aplicación restrictivo, limitando sus efectos solamente a la norma derogada inmediatamente anterior y al cumplimientos de parámetros estrictos, la Corte Constitucional es más garantista, al aplicar la condición más beneficiosa a cualquier norma pretérita derogada en la cual el afiliado haya consolidado su derecho.

En este sentido la Corte Suprema de Justicia señala:

La condición más beneficiosa es un mecanismo que: i) Busca minimizar la rigurosidad propia del principio de aplicación general e inmediata de la Ley, ii) Protege a un grupo poblacional que goza de una situación jurídica concreta, cual es, la satisfacción de las semanas mínimas que exige la reglamentación derogada para acceder a la prestación que cubre la contingencia y iii) $\mathrm{Al}$ ser excepcional, su aplicación necesariamente es restringida y temporal (Sentencia SL-4650, 2017) 
Conforme a lo anterior, para la Corte Suprema de Justicia y Sala Laboral, el derecho a conservar la expectativa legítima es de carácter temporal, pues limita la aplicación del principio de la condición más beneficiosa a la última ley derogada, a manera de ejemplo, se puede decir que un afiliado fue declarado inválido o falleció en vigencia de la Ley 860 (2003) o Ley 797 (2003), respectivamente, sólo tendría derecho a la pensión si consolidó la expectativa legítima al amparo de la Ley 100 (1993) sin que sea posible continuar explorando la consolidación del principio en disposiciones más antiguas, mientras, la Corte Constitucional al permitir explorar la existencia del derecho en todas las disposiciones anteriormente derogadas, por que según el ejemplo anterior no solo buscaría la consolidación del derecho en la Ley 100 (1993), sino también en el Acuerdo 049 (Decreto 048, 1990) y en el Acuerdo 224 (Decreto 3041, 1967).

En tal sentido la Corte constitucional (Sentencia SU-442, 2016) estudió la tutela de un afiliado, de profesión zapatero, con una discapacidad mayor del 50\%, presentada para el año 2013, con 650 semanas acumuladas al sistema pensional entre el 28 de enero de 1980 y el 30 de noviembre de 2008, de las cuales 359 semanas fueron efectuadas de manera independiente, antes de entrar en vigencia la Ley 100 (1993), y 46 semanas adicionales un año antes de la expedición de la Ley 860 (2003). Colpensiones y los jueces de tutela le negaron la pensión de invalidez de origen común, entre otras razones, por no gozar de las 50 semanas dentro de los tres últimos años anteriores a la fecha de estructuración de la invalidez, tal como lo establece la Ley 860 (2003).

De lo anterior, se puede inferir que el afiliado no cumplía con los requerimientos establecidos en la disposición vigente para la fecha en que se determina la estructuración de la invalidez (Ley 860, 2003, Art. $1^{\circ}$ ), como tampoco con los requisitos establecidos en la Ley 100 (1993), pues no contaba con las 26 semanas dentro del año inmediatamente anterior a la fecha del siniestro, pero tenía reunidas más de 300 semanas en vigencia del Acuerdo 049 
aprobado por el Decreto 758 (1990), razón por lo cual, la Corte Constitucional en virtud del principio de la condición más beneficiosa e invocando su propia jurisprudencia, según la cual, el reconocimiento del derecho, bajo este principio, no está limitado a que la expectativa legítima se consolide en vigencia de la norma derogada inmediatamente anterior, sino en cualquiera menos reciente, según reconoce el derecho al peticionario.

Este mismo caso, estudiado bajo la óptica de la Sala Laboral de la Corte Suprema de Justicia no hubiese prosperado; dado que, para esta Corporación la condición más beneficiosa se aplica solamente bajo el amparo de la norma derogada inmediatamente anterior y además que la invalidez se haya estructurado entre el 26 de diciembre de 2003 y el 26 de diciembre de 2006 con apoyo en la Ley 860 (2003). En suma, la Corte Suprema no admite los efectos plusultractivo de las normas derogadas como sí lo acepta la Corte Constitucional en la sentencia de unificación SU-442 (2016), ha que dicho sea de paso, es de obligatorio acatamiento para todos los operadores judiciales.

\section{Tensión y límites de la condición más beneficiosa}

En la forma como se señala de manera tangencial, existe una profunda diferencia entre ambas corporaciones, en cuanto al límite temporal en la aplicación del principio, pues la Sala Laboral de la Corte Suprema de Justicia exige dos condiciones para la aplicación de este principio, el primero hace referencia a la expectativa legítima que debe haberse configurado en la norma derogada inmediatamente anterior a la vigente en la fecha de muerte y la segunda condición esta referida al suceso de la muerte que debe acaecer entre el 29 de enero de 2003 al 29 de enero de 2006, fundamentado en la existencia de una "zona de paso" entre la Ley 100 (1993) y la Ley 797 (2003) que en tiempo corresponde a tres (3) años, tal como lo dispone la Ley 797, lapso durante el cual el afiliado debe reunir 50 semanas para que sus beneficiarios obtengan el derecho a la pensión de sobrevivientes. 
En este sentido, la Sala Laboral de la Corte Suprema de Justicia, bajo los efectos de la Ley 100 (1993, Art. 46) debe continuar produciéndose hasta el 29 de enero de 2006, es decir, si el fallecimiento ocurre después de esta fecha, no aplica el principio de la condición mas beneficiosa aunque se haya consolidado la expectativa legítima en el tiempo señalado, por tanto, los causahabientes no acceden a la pensión de sobrevivientes.

En cambio, para la Corte Constitucional es factible reconocer el principio de la condición mas beneficiosa solamente acreditando que la expectativa legítima se consolidó en cualquier norma derogada, sin que sea necesario que la muerte se produzca entre el 29 de enero de 2003 y el 29 de enero de 2006.

Esta pugna de criterios conlleva a la inseguridad jurídica, resta eficiencia y afecta el acceso a la administración de justicia, en atención, a quién escoja la vía ordinaria para reclamar la pensión de invalidez de origen común o de sobrevivientes, cimentado en esta expectativa, trasegaría sin éxito a través de las diferentes instancias ordinarias, y en últimas acudir a la tutela hasta llegar a la Corte Constitucional, largo camino para recorrer, debido a los jueces ordinarios, quienes actúan como jueces constitucionales, y son proclives a negar prestaciones económicas.

En este mismo sentido Rodríguez, et al (2016) en su análisis normativo jurisprudencial infieren:

En ese orden de ideas, resulta evidente la presencia de tendencia jurídicas disímiles, incluso al interior de la misma Corte Constitucional, que redundan en inconsistencias en el ordenamiento jurídico, generando inseguridad jurídica en la medida que la construcción del precedente judicial no es lo suficientemente coherente para seguirlo (p. 77).

Sin embargo, la Sala Laboral de la Corte Suprema de Justicia, apoya su postura, entre entras razones, en la expectativa legítima de no equipar con el derecho adquirido, criterio que también expuso la Corte Constitucional en la sentencia C-789 
(2002), donde señala que: "el legislador no puede transformar de manera arbitraria las expectativas legítimas que tienen los trabajadores respecto a las condiciones en las cuales aspiran a recibir su pensión".

Así mismo, afirmó la honorable Corte Suprema de Justicia, que la aplicación del principio de la condición más beneficiosa, en la forma como se concibe, cumple con los fines introducidos en el numeral $3^{\circ}$ del artículo 12 del Código Iberoamericano de Seguridad Social, aprobado por la Ley 516 (1999), en el entendido de no ser un principio absoluto al deber acompasarse con los requerimientos del sistema para la prestación del servicio con el fin de no afectar otros principios que le son inherentes como: eficiencia, universalidad, integralidad, participación, progresividad, solidaridad, sostenibilidad financiera y justicia redistributiva.

En cuanto a la sostenibilidad financiera la citada corporación sostiene que no se pueden establecer obligaciones ilimitadas, a cargo del sistema de pensiones, pues estas obligaciones no fueron incluidas en los cálculos actuariales.

Al cotejar los dos enfoques se observa que no existe una colisión de principios, pues, se trata es de la aplicación de uno solo - la condición más beneficiosa - pero, tenemos una diferencia de reglas de interpretación chocando, una expuesta por la Sala Laboral de la Corte Suprema de Justicia y la otra por la Corte Constitucional, con un alcance de obligatoriedad para los operadores de cada jurisdicción, ya que cada una pretende se aplique su propia regla.

Por ello, llegado a este punto, se exponen las reglas inferidas para la Sala Laboral de la Corte Suprema de justicia, la condición más beneficiosa se aplica cuando la expectativa legítima se consolida en la norma derogada inmediatamente anterior a la ley en la cual se causó el siniestro (Sentencia SL-4650, 2017) y además, el suceso de la muerte debe haberse causado entre el 29 de enero de 2003 al 29 de enero de 2006. 
En cambio, para la Corte Constitucional el principio de la condición más beneficiosa encuentra cabida cuando la expectativa legítima se causa en cualquier norma derogada sin importar que sea la última o cualquier otra mas antigua (Sentencia SU-442, 2016). Sobre estas dos reglas se razona cuál debe aplicarse, bajo los principios de favorabilidad e induvio pro operario, teniendo en cuenta como la primera señala que cuando existen dos normas regulando un mismo hecho, se aplica la más favorable al trabajador y el segundo preceptúa que cuando estamos ante una norma con lugar a dos interpretaciones se aplica, igualmente, la que más favorece al trabajador.

$\mathrm{Al}$ momento de ponderar o interpretar los alcances de las dos reglas reguladoras del mismo hecho y que persiguen los mismos resultados, se tiene con fundamento en el principio de favorabilidad que se debería aplicar la regla elaborada por la Corte Constitucional, dado que en ella, el derecho encuentra un mayor campo para su aplicación otorgándole al afiliado una mayor posibilidad de obtener la prestación, en razón a la búsqueda del derecho realizada en las normas derogadas desde la más reciente hasta la más antigua.

Con el mismo objetivo, realizado el análisis de las mencionadas reglas bajo la égida del principio induvio pro operario, se debe aplicar también la de la Corte Constitucional, en razón a la interpretación que se hace de la condición más beneficiosa trayendo como resultado una regla más favorable a la deducida por la Sala Laboral de la Corte Suprema de Justicia, pues, preserva las expectativas legítimas ante cualquier cambio legislativo que afecte negativamente los requisitos para acceder a la pensión de sobrevivientes.

Sin embargo, en la regla establecida por la Corte Constitucional, se advierte que la expectativa legítima tiene unos efectos de permanencia e inamovilidad en el tiempo, similares a la de los derechos adquiridos, lo que no se acompasa con los 
beneficios del régimen de transición pensional, el cual pretende emular, puesto que éste no tiene esa propiedad de fosilizar las expectativas que protege. Tan cierto es, como que el Acto Legislativo 01 (2005) eliminó el régimen de transición, con lo cual se extinguieron todas las expectativas que protegía, presentándose en este caso, una incoherencia en el argumento de la Corte Constitucional.

No obstante todo lo anterior, esta diferencia debería quedar saneada, teniendo en cuenta que mediante la sentencia SU-442 (2016), la Corte Constitucional unificó en este tema la jurisprudencia, manteniendo su postura y advirtiendo que la misma "es vinculante para todas las autoridades, incluidas las judiciales (CP. 1991, Art. 241)". Pero existen antecedentes donde la Corte Suprema de Justicia se ha revelado contra las sentencias de unificación de la Corte Constitucional, no acatando las reglas por ella establecida, tal como se encuentra documentado en la sentencia SL-028 (2018):

En este asunto, la censura invoca el principio de la condición más beneficiosa a fin de que la situación se resuelva bajo el abrigo del Acuerdo 049 de 1990 aprobado por el Decreto 758 del mismo año (1980). Sin embargo, de acudirse a dicho principio, esta norma no tiene cabida, por no corresponder a la norma inmediatamente anterior, pues no es viable hacer una búsqueda de legislaciones anteriores a fin de determinar cuál se ajusta a las condiciones particulares del de cujus o cuál resulta ser más favorable, pues con ello se desconoce que las leyes sociales son de aplicación inmediata y, en principio, rigen hacia futuro (Sentencia SL-028, 2018).

Deviene de lo anterior, que esta corporación a pesar de la sentencia de unificación, antes citada, continúa manteniendo su posición restrictiva en la aplicación del principio, al tener establecido que al tratarse de un precedente horizontal no se encuentra obligada, únicamente debe acatar su propio precedente. 
Además, similar posición adoptó esta corporación en las sentencias SL-028 (2018), SL-9762 (2016), SL-9763 (2016), SL-9764 (2016), SL-14881 (2016), SL-15612 (2016), SL-15617 (2016), SL-15960 (2016) y SL-15965 (2016), denotando fehacientemente su decisión de apartarse de la mencionada jurisprudencia de unificación, generando un nuevo choque de trenes, entre ambas corporaciones, lo cual obstaculiza, como se ha señalado, el acceso a la administración de la justicia y afecta la seguridad jurídica.

Por esto, López (2017) establece las siguientes ideas mencionadas por la Corte Constitucional en la sentencia T-123 (1995):

... Si bien solo la doctrina constitucional de la Corte Constitucional tiene el carácter de fuente obligatoria, es importante considerar que a través de la jurisprudencia criterio auxiliar de la actividad judicial de los altos organos jurisdiccionales por la vía de la unificación doctrinal se realiza el principio de igualdad. Luego, sin perjuicio de que esta jurisprudencia conserve su atributo de criterio auxiliar es razonable exigir, en aras del principio de igualdad en la aplicación de la ley, que los jueces y funcionarios que consideren autónomamente que deben apartarse de la linea jurisprudencia, trasadas por las altas cortes que lo hagan, pero siempre que justifiquen de manera suficiente y adecuada su decisión (p. 107).

Resultado de lo anterior, a pesar de la obligación de aplicar las sentencias de unificación la misma Corte Constitucional tiene establecido que los jueces y funcionarios pueden apartarse de la misma, siempre y cuando fundamenten suficientemente sus providencias, privilegiando de esta manera el principio de igualdad.

En general, cada una de las mencionadas corporaciones tiene establecidos sus propios requisitos, para reconocer la pensión de invalidez de origen común y de sobrevivientes, cuando las mismas se estudian al amparo de la condición mas beneficiosa, los cuales se resumen a continuación: 
TABla 1.

Requisitos

\section{Según la Corte Suprema de} Justicia

\section{Según la Corte Constitucional}

1. Para esta Corporación la condición más beneficiosa se puede aplicar a cualquier norma pretérita derogada en la cual el afilidado haya consolidado una expectativa legitima por reunir la densidad de semanas en ella establecidas.

a) Que al 29 de enero de 2003 el afiliado estuviese cotizando.

b) Que hubiese aportado 26 semanas en cualquier tipo, antes del 29 de enero de 2003.

c) Que la muerte se produzca entre el 29 de enero de 2003 y el 29 de enero de 2006.

d) Que al momento del fallecimiento estuviese cotizando.

e) Que hubiese cotizado 26 semanas en cualquier tiempo, antes del deceso.

2. Con base en el anterior criterio

la Corte Constitucional reconoció la pensión de invalidez de origen común estructurada en vigencia de la Ley 860 (2003), pero consolidaron una expectativa legitima a la luz de cualquier norma anterior, como la Ley 100 (1993), el Acuerdo 049 (Decreto 048, 1990), el Acuerdo 224 aprobado por el Decreto 3041 (1967) y reformado a su vez por el Decreto 232 (1984).

2. Cuando el afiliado no se encuentra cotizando al momento del cambio normativo debe cumplir los siguientes requisitos.

a) Que al 29 de enero de 2003 el afiliado no estuviese cotizando.

b) Que hubiese aportado 26 semanas en el año que antecede a dicha data, es decir, entre el 29 de enero de 2002 y el 29 de enero de 2003.

c) Que la muerte se produzca entre el 29 de enero de 2003 y el 29 de enero de 2006.

d) Que al momento del deceso no estuviese cotizando.

e) Que hubiese cotizado 26 semanas en

3. Este criterio de la Corte es pacífico desde el año 2010, tal como se observa en los diferentes fallos de tutela:

Año 2010: T-1058, T-186, T-826

Año 2011: T-062A, T-762, T-668

Año 2012: T-434

Año 2013: T-886, T-553, T-872, T-576

Año 2014: T-717, T-953, T-208, T-110, T-556, T-012, T-549, T-910

Año 2016: T-112, T-065, T-826, T-194, T-304, T-137

SU-442/2016, en la cual la corporación unificó la jurisprudencia, con advertencia de obligatoria para todos los operadores judiciales. el año que antecede al fallecimiento. 
La Tabla 1 muestra los requisitos establecidos por la Sala Laboral de la Corte Suprema de Justicia para la pensión de sobrevivientes, los cuales aplican también para la pensión de invalidez de origen común, excepto en relación con los límites temporales, que están fijados entre el 26 de diciembre de 2003 y el 26 de diciembre 2006, conforme a la interpretación que se hace de la Ley 860 (2003). La Corte Constitucional aplica los mismos requisitos para ambas prestaciones al no contemplar límites temporales para conservar la expectativa legítima, cuando de resolver estos casos se trata.

\section{Conclusiones}

Del anterior estudio el principio de la condición más beneficiosa surge como un instrumento idóneo para proteger los derechos de las personas que consolidaron una expectativa legítima en vigencia de normas derogadas, ante la ausencia de un régimen de transición que los proteja, reconociéndoles la pensión de invalidez de origen común y de sobrevivientes, en los casos en que el afiliado reunió el número de semanas establecidas en leyes derogadas, a pesar de que la invalidez o la muerte ocurrieron en vigor de disposiciones posteriores.

Con la aplicación de este principio, la Sala Laboral de la Corte Suprema de Justicia busca atenuar: i) el rigor que tiene el principio de aplicación inmediata de la ley y ii) proteger situaciones jurídicas concretas reconociendo un efecto ultractivo a la norma derogada, con el fin de que los requisitos alcanzados bajo su imperio permitan al afiliado obtener una pensión a pesar de no lograr reunir los establecidos en la ley vigente al momento que ocurrió la invalidez o el fallecimiento.

Adicionalmente al requisito anterior, la Corte Suprema de Justicia -Sala Laboral -, exige que tratándose de la pensión de sobrevivientes también debe verificarse que la muerte haya ocurrido entre el 29 de enero de 2003 y el 29 de enero de 2006; y la invalidez de origen común se haya estructurado entre el 
26 de diciembre de 2003 y el 26 de diciembre de 2006, tal como se deduce de la Ley 797 (2003) y de la Ley 860 (2003) respectivamente.

De acuerdo al anterior contexto, la interpretación que hace la Corte Suprema de Justicia sobre la manera como se debe aplicar la condición más beneficiosa tiene un carácter restrictivo, procurando proteger los principios de proporcionalidad, sostenibilidad financiera, no equiparar los derechos consolidados con las expectativas legítimas y colocarle un límite temporal a los efectos ultractivos de las normas derogadas.

De otra parte, para la Corte Constitucional el citado principio de la condición más beneficiosa debe aplicarse en los eventos en que la expectativa legítima se configura en cualquier norma derogada independiente de la inmediatamente anterior norma o cualquier otra mas antigua, sin considerar la época posterior en la cual se define la invalidez u ocurre el fallecimiento.

Las anteriores posturas originaron dos reglas que contienen diferentes campos de aplicación, resultado más garantista la de la Corte Constitucional a la luz del principio de favorabilidad y del induvio pro operario por ser la más favorable y haberse originado en una interpretación mas favorable de la condición más beneficiosa.

Para sanear la anterior diferencia de criterio, la Corte Constitucional expidió la sentencia SU-442 (2016), con el fin de unificar la jurisprudencia inclinándose a favor de su propia regla y haciéndola "vinculante para todas las autoridades administrativas incluidos los operadores judiciales".

Conforme a lo expuesto, se comparte la posición adoptada por la Corte Constitucional, al proteger su regla al afiliado de los constantes y continuos cambios en los requisitos para acceder a los beneficios pensionales. No es fácil para un trabajador mantener una historia de cotizaciones razonablemente estables debido a la falta de oportunidades laborales, la restricción 
para acceder al empleo después de haber cumplido determinada edad, además, por estar la condición más beneficiosa edificada en un cúmulo de derechos fundamentales generadores de una especial protección, tales como: "la seguridad social como un derecho irrenunciable" (C.P. 1991, Art. 48), "el principio de solidaridad" (C.P. 1991, Art. 48; C.P. 1991, Art. 95), "buena fe" (C.P. 1991, Art. 83), "no menoscabar la dignidad humana ni los derechos de los trabajadores" (C.P. 1991, Art. 53); los cuales deben "interpretarse a la luz de los tratados internacionales de derechos humanos ratificados por Colombia" (CP. 1991, Art. 93), e incorporados a la legislación interna, entre los cuales se reseña el Protocolo de San Salvador, aprobado mediante la Ley 319 (1996) que señala a la seguridad social como el derecho que tiene toda persona a que se le "proteja contra las contingencias de la vejez y de la incapacidad que la imposibilite física o mentalmente para obtener los medios para llevar una vida digna y decorosa" (Art. 9) y "el principio de favorabilidad" (C.P. 1991, Art. 53), entre otros.

De otra parte, se señala como una vez unificada la jurisprudencia por la Corte Constitucional, como guardiana de la constitución, al todos los jueces deber acatar su pronunciamiento en beneficio de la administración de justicia, de la seguridad jurídica, pero sobre todo, en beneficio del conglomerado social. Sin embargo, la Corte Suprema de Justicia en la Sala Laboral tiene establecido que sólo esta obligada a seguir su propio precedente, con esta postura justifica el por qué de su disenso, especialmente en los casos en que no comparte la posición de la Corte Constitucional.

Finalmente, se puede concluir como la regla más favorable para el conglomerado social, en cuanto al reconocimiento de la pensión de invalidez de origen común y de sobreviviente, es la expuesta por la Corte Constitucional en atención a que sus efectos favorecen a un mayor número de personas del territorio nacional. 


\section{REFERENCIAS}

Hernández, J., Chumaceiro, A., Ziritt, G. y Acurero, M. (2018).

Cultura para la paz en Colombia. Una aproximación desde las políticas publicas. Opción, 34(86). 612 - 641.

López, M. (2017). Módulo interpretación constitucional. Bogotá, D.C.: CSJ.

República de Colombia. Asamblea Nacional Constituyente.

(1991). Artículo 1. [Constitución política de Colombia].

Gaceta Constitucional, 1(114). 3. Recuperado de http://

babel.banrepcultural.org/cdm/compoundobject/collection/

p17054coll26/id/3850/show/3743/rec/8

República de Colombia. Asamblea Nacional Constituyente.

(1991). Artículo 2. [Constitución política de Colombia]. Gaceta Constitucional, 1(114). 3.

República de Colombia. Asamblea Nacional Constituyente.

(1991). Artículo 9. [Constitución política de Colombia]. Gaceta Constitucional, 1(114). 3.

República de Colombia. Asamblea Nacional Constituyente.

(1991). Artículo 13. [Constitución política de Colombia].

Gaceta Constitucional, 1(114). 3.

República de Colombia. Asamblea Nacional Constituyente.

(1991). Artículo 47. [Constitución política de Colombia]. Gaceta Constitucional, 1(114). 5.

República de Colombia. Asamblea Nacional Constituyente.

(1991). Artículo 48. [Constitución política de Colombia].

Gaceta Constitucional, 1(114). 5.

República de Colombia. Asamblea Nacional Constituyente.

(1991). Artículo 53. [Constitución política de Colombia].

Gaceta Constitucional, 1(114). 5.

República de Colombia. Asamblea Nacional Constituyente. (1991). Artículo 83. [Constitución política de Colombia]. Gaceta Constitucional, 1(114). 6. 
República de Colombia. Asamblea Nacional Constituyente. (1991). Artículo 93. [Constitución política de Colombia]. Gaceta Constitucional, 1(114). 7.

República de Colombia. Asamblea Nacional Constituyente. (1991). Artículo 95. [Constitución política de Colombia]. Gaceta Constitucional, 1(114). 7.

República de Colombia. Asamblea Nacional Constituyente. (1991). Artículo 241. [Constitución política de Colombia]. Gaceta Constitucional, 1(114). 16-17.

República de Colombia. Congreso de la República. (29 de diciembre de 2003). Por la cual se reforman algunas disposiciones del Sistema General de Pensiones previsto en la Ley 100 de 1993. [Ley 860]. DO: 45.415.

República de Colombia. Congreso de la República. (29 de enero de 2003). Por la cual se reforman algunas disposiciones del sistema general de pensiones previsto en la Ley 100 de 1993 y se adoptan disposiciones sobre los Regímenes Pensionales exceptuados y especiales. [Ley 797]. DO: 45.079.

República de Colombia. Congreso de la República. (4 de agosto de 2003). Por medio de la cual se aprueba el "Código Iberoamericano de Seguridad Social". [Ley 516]. DO: 43.656.

República de Colombia. Congreso de la República. (24 de septiembre de 1996). Por medio de la cual se aprueba el Protocolo Adicional a la Convención Americana sobre Derechos Humanos en Materia de Derechos Económicos, Sociales y Culturales "Protocolo de San Salvador». [Ley 319]. DO: 42.884 .

República de Colombia. Congreso de la República. (23 de diciembre de 1993). Por la cual se crea el sistema de seguridad social integral y se dictan otras disposiciones. [Ley 100]. DO: 41.148.

República de Colombia. Corte Constitucional. (18 de Agosto de 2016). Sentencia SU-442. Exp. T-5383796. [MP: María Victoria Calle Correa]. 
República de Colombia. Corte Constitucional. (15 de junio de 2016). Sentencia T-304. Exp. T-5.395.331. [MP: Jorge Ignacio Pretelt Chaljub].

República de Colombia. Corte Constitucional. (21 de abril de 2016). Sentencia T-194. Exp. T-5301858, T-5309729, T5314829 y T-5314910. [MP: Jorge Ignacio Pretelt Chaljub].

República de Colombia. Corte Constitucional. (14 de marzo de 2016). Sentencia T-137. Exp. T-5261587. [MP: Luis Ernesto Vargas Silva].

República de Colombia. Corte Constitucional. (4 de marzo de 2016). Sentencia T-112. Exp. T-5.206.885. [MP: Luis Guillermo Guerrero Pérez].

República de Colombia. Corte Constitucional. (16 de febrero de 2016). Sentencia T-065. Exp. T-5.161.226, T-5.169.150 y T-5.176.711 (acumulados). [MP: Luis Guillermo Guerrero Pérez].

República de Colombia. Corte Constitucional. (17 de Abril de 2015). Sentencia T-190. Exp. T-4.610.966. [MP: Luis Guillermo Guerrero Pérez].

República de Colombia. Corte Constitucional. (4 de diciembre de 2014). Sentencia T-953. Exp. T-4450903. [MP: María Victoria Calle Correa].

República de Colombia. Corte Constitucional. (26 de noviembre de 2014). Sentencia T-910. Exp. T-4.454.118, T-4.450.411, T-4.441.363, T-4.447.525 y T-4.455.344. [MP: Mauricio González Cuervo].

República de Colombia. Corte Constitucional. (16 de septiembre de 2014). Sentencia T-717. Exp. T-4349013, T-4349611, T-4350198, T-4360082, T-4363536, T-4364489 y T-4365133 (acumulados). [MP: María Victoria Calle Correa]. 
República de Colombia. Corte Constitucional. (22 de julio de 2014). Sentencia T-549. Exp. T-4.190.630, T-4.192.231, T-4.200.034, T-4.207.853, T-4.208.797, T-4.214.033, T-4.223.178 y T-4.224.997 (Acumulados). [MP: Luis Ernesto Vargas Silva].

República de Colombia. Corte Constitucional. (5 de noviembre de 2014). Sentencia T-826. Exp. T-4406447. [MP: Gloria Stella Ortiz Delgado].

República de Colombia. Corte Constitucional. (1 de abril de 2014). Sentencia T-208. Exp. T- 4.117.321 y T-4.138.521 (Acumulados). [MP: Luis Guillermo Guerrero Pérez].

República de Colombia. Corte Constitucional. (3 de marzo de 2014). Sentencia T-110. Exp. T-4.089.300. [MP: Gabriel Eduardo Mendoza Martelo].

República de Colombia. Corte Constitucional. (21 de enero de 2014). Sentencia T-012. Exp. T- 4049725, T-4062695 y T-4063277. [MP: Jorge Ignacio Pretelt Chaljub].

República de Colombia. Corte Constitucional. (3 de diciembre de 2013). Sentencia T-886. Exp. T- 3.974.993, T- 3.983.906, T-3.984.021， T-3.985.384， T- 3.986.393， T- 3.991.396 (Acumulados). [MP: Luis Guillermo Guerrero Pérez].

República de Colombia. Corte Constitucional. (2 de diciembre de 2013). Sentencia T-872. Exp. T-4.010.076. [MP: Gabriel Eduardo Mendoza Martelo].

República de Colombia. Corte Constitucional. (18 de noviembre de 2013) Sentencia T-832A. Expediente T-3962356. [MP: Luis Ernesto Vargas Silva].

República de Colombia. Corte Constitucional. (26 de agosto de 2013). Sentencia T-576. Exp. T-3.852.539 y T-3.852.578. [MP: Alberto Rojas Ríos].

República de Colombia. Corte Constitucional. (22 de agosto de 2013). Sentencia T-553. Exp. T-3862736. [MP: Gabriel Eduardo Mendoza Martelo]. 
República de Colombia. Corte Constitucional. (12 de junio de 2012). Sentencia T-434. Exp. T-3.345.197. [MP: Humberto Antonio Sierra Porto].

República de Colombia. Corte Constitucional. (8 de septiembre de 2011). Sentencia T-668. Exp. T-3052755 y T- 3053025. [MP: Nilson Pinilla Pinilla].

República de Colombia. Corte Constitucional. (7 de octubre de 2011). Sentencia T-762. Exp. T-3085282. [MP: María Victoria Calle Correa].

República de Colombia. Corte Constitucional. (4 de febrero de 2011). Sentencia T-062A. Exp. T -2.740.402. [MP: Mauricio González Cuervo].

República de Colombia. Corte Constitucional. (16 de diciembre de 2010). Sentencia T-1058. Exp. T-2.186.444, T-2.186.608, T-2.186.868, T-2.193.856, T-2.161.387, T-2.231.681, T-2.253.643 y T-2.253.769 (Acumulados). [MP: Gabriel Eduardo Mendoza Martelo].

República de Colombia. Corte Constitucional. (20 de octubre de 2010). Sentencia T-826. Ex. T-2.714.362. [MP: Jorge Ignacio Pretelt Chaljub].

República de Colombia. Corte Constitucional. (18 de marzo de 2010). Sentencia T-186. Exp. T- 2.450.097 - T-2.457.197 T-2.456.430. [MP: Jorge Ignacio Pretelt Chaljub].

República de Colombia. Corte Constitucional. (13 de febrero de 2003). Sentencia SU-120. Exp. T-406.257, T-453.539 у T503.695. [MP: Álvaro Tafur Galvis].

República de Colombia. Corte Constitucional. (24 de Septiembre de 2002). Sentencia C-789. Exp. D-3958. [MP: Rodrigo Escobar Gil].

República de Colombia. Corte Constitucional. (21 de marzo de 1995). Sentencia T-123. Exp. T-48378. [MP: Eduardo Cifuentes Muñoz]. 
República de Colombia. Corte Suprema de Justicia. Sala de

Casación Laboral. (24 de Enero de 2018). Sentencia SL-

028. Rad. 59012. [MP: Fernando Castillo Cadena]

República de Colombia. Corte Suprema de Justicia. Sala de

Casación Laboral. (25 de enero de 2017). Sentencia SL4650. Rad. 45262. [MP: Fernando Castillo Cadena y Gerardo Botero Zuluaga].

República de Colombia. Corte Suprema de Justicia. Sala de

Casación Laboral. (26 de octubre de 2016). Sentencia SL-

15965. Rad. 53714. [MP: Clara Dueñas Quevedo].

República de Colombia. Corte Suprema de Justicia. Sala de

Casación Laboral. (26 de octubre de 2016). Sentencia SL-

15960. [MP: Clara Cecilia Dueñas Quevedo].

República de Colombia. Corte Suprema de Justicia. Sala de

Casación Laboral. (19 de octubre de 2016). Sentencia SL-

15617. [MP: Clara Dueñas Quevedo].

República de Colombia. Corte Suprema de Justicia. Sala de

Casación Laboral. (19 de octubre de 2016). Sentencia SL-

15612. [MP: Clara Dueñas Quevedo].

República de Colombia. Corte Suprema de Justicia. Sala de

Casación Laboral. (05 de octubre de 2016). Sentencia SL-

14881. [MP: Clara Dueñas Quevedo].

República de Colombia. Corte Suprema de Justicia. Sala de

Casación Laboral. (13 de julio de 2016). Sentencia SL-9764.

[MP: Clara Dueñas Quevedo].

República de Colombia. Corte Suprema de Justicia. Sala de

Casación Laboral. (13 de julio de 2016). Sentencia SL-9763.

[MP: Clara Dueñas Quevedo].

República de Colombia. Corte Suprema de Justicia. Sala de

Casación Laboral. (13 de julio de 2016). Sentencia SL-9762.

[MP: Clara Dueñas Quevedo].

República de Colombia. Minjusticia. (23 de diciembre de 1993).

Por la cual se crea el sistema de seguridad social integral y se dictan otras disposiciones. [Decreto 758]. DO: 39.303. 
República de Colombia. Mintrabajo. (14 de enero de 1967). Por el cual se aprueba el reglamento general del seguro social obligatorio de invalidez, vejez y muerte. [Decreto 3041]. DO: 32.126.

República de Colombia. Presidencia de la República. (25 de julio de 2005). Por el cual se adiciona el artículo 48 de la Constitución Política. [Acto legislativo 01]. DO: 45.980.

República de Colombia. Presidencia de la República. (31 de enero de 1984). Por el cual se aprueba el Acuerdo número 019, emanado del Consejo Nacional de los Seguros Sociales Obligatorios. [Decreto 232]. DO: 36.490.

Rodríguez, M., Cuervo, H., Ponce, G., Suárez, A., Urrego, D., Benavides, D., Moreno, I. y Restrepo, J. (2016). La pensión de invalidez en el régimen de prima media: Análisis normativo - jurisprudencial. Bogotá: Universidad Externado de Colombia: Colpensiones.

Romero, L. e Ibarra, J. (2017). La pensión especial anticipada de vejez: Un análisis desde la perspectiva de la teoría de la eficacia simbólica del derecho. Advocatus, 14(28). 41-57. https://doi.org/10.18041/0124-0102/advocatus.29.1656 
${ }^{1}$ Este es un artículo de reflexión, cuyo interés surgió por la tensión existente actualmente entre la Corte Constitucional y la Sala Laboral de la Corte Suprema de Justicia, sobre la aplicación de la condición más beneficiosa, cuando existe una expectativa legítima consolidada al amparo de normas derogadas; y también, por el deseo de conocer la postura adoptada por la Sala Laboral de la Corte Suprema de Justicia frente a la sentencia de unificación SU-442 (Corte Constitucional, 2016).

${ }^{2}$ Alberto E. Barrios Lozano es abogado y Contador Público. Especialista en Derecho Laboral de la Universidad Javeriana (Colombia) y Especialista en Derecho Administrativo de la Universidad Libre (Colombia). Magíster en Derecho Procesal de la Universidad de Medellín (Colombia) y Magíster en Derecho del Trabajo y de la Seguridad Social de la Universidad del Norte (Colombia).

${ }^{3}$ Ligia Romero Marín es abogada, Especialista en Derecho Laboral y Seguridad Social de la Universidad Libre (Colombia), Especialista en Derecho Administrativo de la Universidad Libre (Colombia) y Especialista en Estudios Pedagógicos en la Universidad de la Costa (Colombia). Magíster en Derecho de la Universidad del Norte (Colombia) y Doctora en Ciencias Jurídicas de la Universidad para la Cooperación Internacional de México. 